\title{
Intravenous Dexamethasone Attenuated Inflammation and Influenced Apoptosis of Lung Cells in an Experimental Model of Acute Lung Injury
}

\author{
P. KOSUTOVA ${ }^{1,2}$, P. MIKOLKA ${ }^{1,2}$, S. BALENTOVA $^{3}$, M. ADAMKOV ${ }^{3}$, \\ M. KOLOMAZNIK ${ }^{1,2}$, A. CALKOVSKA ${ }^{1,2}$, D. MOKRA ${ }^{1,2}$
}

${ }^{1}$ Biomedical Center Martin, Jessenius Faculty of Medicine in Martin, Comenius University in Bratislava, Martin, Slovakia, ${ }^{2}$ Department of Physiology, Jessenius Faculty of Medicine in Martin, Comenius University in Bratislava, Martin, Slovakia, ${ }^{3}$ Department of Histology and Embryology, Jessenius Faculty of Medicine in Martin, Comenius University in Bratislava, Martin, Slovakia

Received March 25, 2016

Accepted October 26, 2016

\section{Summary}

Acute lung injury (ALI) is characterized by diffuse alveolar damage, inflammation, and transmigration and activation of inflammatory cells. This study evaluated if intravenous dexamethasone can influence lung inflammation and apoptosis in lavage-induced ALI. ALI was induced in rabbits by repetitive saline lung lavage (30 ml/kg, 9 93 -times). Animals were divided into 3 groups: ALI without therapy (ALI), ALI treated with dexamethasone i.v. $(0.5 \mathrm{mg} / \mathrm{kg}$, Dexamed; ALI+DEX), and healthy non-ventilated controls (Control). After following $5 \mathrm{~h}$ of ventilation, ALI animals were overdosed by anesthetics. Total and differential counts of cells in bronchoalveolar lavage fluid (BAL) were estimated. Lung edema was expressed as wet/dry weight ratio. Concentrations of IL-1B, IL-8, esRAGE, S1PR3 in the lung were analyzed by ELISA methods. In right lung, apoptotic cells were evaluated by TUNEL assay and caspase-3 immunohistochemically. Dexamethasone showed a trend to improve lung functions and histopathological changes, reduced leak of neutrophils $(P<0.001)$ into the lung, decreased concentrations of pro-inflammatory IL-1 $\beta(P<0.05)$ and marker of lung injury esRAGE $(P<0.05)$, lung edema formation $(P<0.05)$, and lung apoptotic index $(P<0.01)$, but increased immunoreactivity of caspase- 3 in the lung $(P<0.001)$. Considering the action of dexamethasone on respiratory parameters and lung injury, the results indicate potential of this therapy in ALI.

\section{Key words}

Dexamethasone • Inflammation • Lung injury • Programmed cell death • Edema

\section{Corresponding author}

D. Mokrá, Biomedical Center Martin, Jessenius Faculty of Medicine in Martin, Comenius University in Bratislava (JFM CU) and Department of Physiology JFM CU, Mala Hora 4C, SK-03601 Martin, Slovakia. E-mail: mokra@jfmed.uniba.sk

\section{Introduction}

Acute respiratory distress syndrome (ARDS) and its less serious form called acute lung injury (ALI) can be caused by many reasons including sepsis, inhalational injury or aspiration. ALI/ARDS develops three overlapping phases: an exudative phase with acute neutrophilic inflammation and lung edema formation; a fibroproliferative phase with formation of alveolar hyaline membranes and varying degree of interstitial fibrosis, and finally, a resolution (Matthay and Zemans 2011).

Increased permeability of the alveolar-capillary membrane resulting from injury to the endothelium and epithelial alveolar cells is the hallmark of this acute event. Damaged cell surface enables an influx of proteinrich edema fluid and migration of inflammatory cells, particularly neutrophils, into the lung under influence of chemoattractants, such as IL-8. Subsequently, the cells 
are activated and produce a huge spectrum of bioactive substances (Grommes and Soehnlein 2011). Within 1-2 weeks after the injury, alveolar edema is reabsorbed by active transport from the distal air spaces into the lung interstitium. Type II alveolar cells proliferate to cover the injured basement membrane and differentiate into the type I alveolar cells (Matthay and Zemans 2011). Clearance of neutrophils from the injured lung is realized particularly through a programmed cell death (apoptosis). Nevertheless, apoptosis of cells contributes also to the pathogenesis of acute phase of ALI/ARDS, where increased apoptosis of epithelial cells and delayed apoptosis of neutrophils have been described (Galani et al. 2010).

Several groups of pharmacological agents including glucocorticoids (GCs) have been recently tested in the treatment of ALI/ARDS. GCs have appeared to be particularly perspective as they provide multiple anti-inflammatory, antiedematous and pulmonary vasodilatory action through their genomic and nongenomic mechanisms (Coutinho and Chapman 2011). In addition, GCs control apoptosis and cell survival in a tissue- or cell-specific manner. For instance, dexamethasone is known as a potent inhibitor of lung epithelial cell apoptosis (Wen et al. 1997). On the other hand, GCs induce apoptosis of eosinophils, but delay apoptosis of neutrophils, whereas this effect is dosedependent. Effect of GCs on thymocytes depends on their developmental stage, whereas mature $\mathrm{T}$ cells are relatively resistant to $\mathrm{GC}$-induced apoptosis (McColl et al. 2007). However, previous studies where GCs (particularly methylprednisolone) were delivered in ALI/ARDS provided controversial results (Meduri et al. 2009, Tang et al. 2009, Hough 2014). Contrary, dexamethasone administered in a model of meconium aspiration syndrome, another form of ALI, exerted rapid positive effects on the lung function (Mokra et al. 2007). Therefore, this study was performed to test effects of dexamethasone in a saline-lavage model of ALI which is known as a model of surfactant depletion or washout (Wang et al. 2008).

\section{Methods}

Animals

In the study, adult New Zealand white rabbits (supplied by VELAZ Animal Breeding Station, Czech Republic) of both genders with a mean body weight (b.w.) of $3.0 \pm 0.3 \mathrm{~kg}$ were used.

\section{General design of experiments}

Experiments were carried out in accordance with the European Guidelines on Laboratory Animal Care, and were authorized by the local Ethics Committee of JFM CU in Martin (EK 1385/2013) and National Veterinary Board of Slovak Republic (Ro-3122/13-221).

Animals were anesthetized with intramuscular ketamine (20 mg/kg b.w.; Narketan, Vétoquinol, UK) and xylazine ( $5 \mathrm{mg} / \mathrm{kg}$ b.w.; Xylariem, Riemser, Germany), followed by an infusion of ketamine $(20 \mathrm{mg} / \mathrm{kg} / \mathrm{h})$. Catheters were inserted into the femoral artery and right atrium for sampling the blood, and into the femoral vein to administer anesthetics. Tracheotomy was performed and endotracheal cannula inserted. One group of animals which served as healthy non-ventilated controls (Control group, $n=6$ ) were overdosed by anesthetics at this stage of experiment. Other animals were given pipecuronium bromide $\quad(0.3 \mathrm{mg} / \mathrm{kg}$ b.w. $/ 30 \mathrm{~min}$; Arduan, Gedeon Richter, Hungary) to avoid spontaneous breathing and were ventilated with a pressure-controlled ventilator (Beat-2, Chirana, Slovakia) with frequency (f) of 30/min, fraction of inspired oxygen $\left(\mathrm{FiO}_{2}\right)$ of 1.0 , inspiration time (Ti) $50 \%$, peak inspiratory pressure (PIP)/positive endexpiratory pressure (PEEP) of $1.5 / 0.3 \mathrm{kPa}$ and tidal volume $\left(\mathrm{V}_{\mathrm{T}}\right)$ of $6-8 \mathrm{ml} / \mathrm{kg}$ b.w. After $15 \mathrm{~min}$ of stabilization, respiratory parameters were recorded and blood gases and oxygen saturation (Sat. $\mathrm{O}_{2}$ ) analyzed (RapidLab 348, Siemens, Germany). Model of ALI was induced by repetitive lung lavage with $0.9 \%$ saline $\left(30 \mathrm{ml} / \mathrm{kg}\right.$ b.w., $\left.37^{\circ} \mathrm{C}\right)$ which was instilled into the endotracheal cannula in the semi-upright right and left lateral positions of the animal and was immediately suctioned by a suction device as previously described (Wang et al. 2008, Ronchi et al. 2011). Lavage was performed 6-12-times, until $\mathrm{PaO}_{2}$ decreased to $<26.7 \mathrm{kPa}$ in $\mathrm{FiO}_{2} 1.0$ in two measurements at 5 and 15 min after the lavage. When criteria of the ALI model were full-filled, one group of animals was treated with intravenous dexamethasone $(0.5 \mathrm{mg} / \mathrm{kg}$, Dexamed; ALI+DEX group, $n=6$ ), other group of animals with ALI was non-treated (ALI group, $n=6$ ). Animals of both ALI groups were oxygen-ventilated $\left(\mathrm{FiO}_{2} 1.0\right.$, f. 30/min, PIP/PEEP $1.5 / 0.3 \mathrm{kPa}, \mathrm{V}_{\mathrm{T}} 6-8 \mathrm{ml} / \mathrm{kg}$ b.w.) for an additional $5 \mathrm{~h}$ and blood gases and respiratory parameters were measured at $0.5,1,2,3,4$, and $5 \mathrm{~h}$ after the treatment. At the end of experiment, blood samples were taken and animals were overdosed by anesthetics. 
Measurement of respiratory parameters and calculation of indexes

Tracheal airflow and $\mathrm{V}_{\mathrm{T}}$ were measured by a heated Fleisch head connected to a pneumotachograph. Airway pressure was registered via a pneumatic catheter placed in the tracheal tube and connected to an electromanometer. Mean airway pressure (MAP) was calculated as: $\mathrm{MAP}=(\mathrm{PIP}+\mathrm{PEEP}) / 2$. Oxygenation index (OI) was calculated as: $\mathrm{OI}=\left(\mathrm{MAP} \times \mathrm{FiO}_{2}\right) / \mathrm{PaO}_{2}$. Alveolar $\mathrm{pO}_{2}\left(\mathrm{P}_{\mathrm{A}} \mathrm{O}_{2}\right)$ and pulmonary venous shunt $(\mathrm{Qs} / \mathrm{Qt})$ were calculated as described elsewhere (Chiang 1968).

\section{Counting of cells in the BAL fluid}

After sacrificing the animal, lung and trachea were excised. Left lung was 3-times lavaged by saline $\left(0.9 \% \mathrm{NaCl}, 37^{\circ} \mathrm{C}\right.$, individual doses of $10 \mathrm{ml} / \mathrm{kg}$ b.w. $)$ and bronchoalveolar lavage (BAL) fluid was centrifuged at $1500 \mathrm{rpm}$ for $10 \mathrm{~min}$. Total number of cells in the BAL fluid was determined microscopically in a counting chamber. Differential count of cells in the sediment was evaluated microscopically after staining by MayGrünwald/Giemsa-Romanowski.

\section{Markers of inflammation and lung injury}

Samples of right lung tissue were taken and prepared for additional analyses.

Preparation of the lung tissue homogenate. Lung tissue was homogenized (5-times for $25 \mathrm{~s}, 1200 \mathrm{rpm}$ ) in an ice-cold phosphate buffer ( $\mathrm{pH}$ 7.4). Homogenates were then 3-times freezed and centrifuged (12000 rpm, $15 \mathrm{~min}$, $4{ }^{\circ} \mathrm{C}$ ). Final supernatants were stored at $-70^{\circ} \mathrm{C}$ until the analysis was performed. Protein concentrations were determined according to Lowry et al. (1951), using bovine serum albumin as a standard.

Measurement of markers of inflammation and lung injury by enzyme-linked immunosorbent assay (ELISA). Concentrations of proinflammatory cytokines (IL-1 $\beta$, IL-8) and markers of injury to lung epithelial cells [endogenous secretory receptor for advanced glycation end-products (esRAGE)] and endothelial cells [sphingosine-1-phosphate receptor-3 (S1PR3)] were measured in the lung homogenates using rabbit-specific ELISA kits (USCN kits for interleukins, ABIN for esRAGE and S1PR3) according to the manufacturers' instructions. Results were analyzed spectrophotometrically at $450 \mathrm{~nm}$ using an ELISA microplate reader.

\section{Histomorphological investigation of the lung tissue}

For histomorphological analysis, upper right lung lobe was fixed in buffered $4 \%$ formaldehyde. After paraffin embedding sections of $4 \mu \mathrm{m}$ were cut on microtome. The slides were further deparaffinized, rehydrated in descending grades of ethanol and stained with hematoxylin. After differentiation and washing, the slides were immersed in eosin dye, dehydrated and finally coverslipped with Entellan mounting medium (Merck Millipore, Germany). To score lung injury and inflammation, lung tissue samples were screened for the following signs: 1) atelectasis, 2) emphysema, 3) hemorrhagia, and 4) PMN infiltration. Samples were evaluated by an experienced histopathologist blinded to the grouping of animals, and results were scored of 0-3 with 0 as absent (normal), 1 as mild, 2 as moderate, and 3 as severe. The total injury score was calculated as a sum of these scores.

\section{Apoptosis assays}

In situ labeling of DNA strand breaks by TUNEL method. The lung tissue was immersed in $4 \%$ formaldehyde. After paraffin embedding, slides of $4 \mu \mathrm{m}$ thick were cut on microtome followed by deparaffinization and pretreatment with a proteinase $\mathrm{K}$. The tissue sections were processed by DeadEnd ${ }^{\mathrm{TM}}$ Colorimetric TUNEL System (Promega, USA) to label the fragmented DNA of apoptotic cells. In this method, biotinylated nucleotide is incorporated at the 3'-OH DNA ends using the Terminal Deoxynucleotidyl Transferase, Recombinant, (rTdT) enzyme. Horseradish peroxidaselabeled streptavidin (Streptavidin HRP) is then bound to these biotinylated nucleotides. For detection of nucleotides and blocking endogenous peroxidases, the sections were incubated with $0.3 \% \mathrm{H}_{2} \mathrm{O}_{2}$. Color of sections was developed after incubation with diaminobenzidine (DAB)-chromogen solution. The sections were then counterstained with Mayer's hematoxylin and mounted with a Permount (Fisher, USA). The slides were viewed with the microscope (Olympus BX41, Japan). The image capture was performed with Quick Photo Micro software, version 2.2 (Olympus, Japan). The apoptotic index of bronchial and alveolar epithelium was calculated as the percentage of TUNEL immunoreactive (TUNEL-IR) dark brownstained nuclei in a total 100 nuclei randomly counted from three sites within each section.

Immunohistochemistry for activated caspase-3. After deparaffinization, revitalisation and rehydratation, the tissue slides were treated with $3 \% \mathrm{H}_{2} \mathrm{O}_{2}$ for $10 \mathrm{~min}$ for blocking endogenous peroxidases. Washing with Tris 
buffer was used after each handling step. The sections were incubated with the primary antibody rabbit anticaspase 3 (1:500; Bioss, USA) for $30 \mathrm{~min}$ at room temperature. The specimen is then incubated by sequential $10 \mathrm{~min}$ incubation with biotinylated anti-rabbit secondary antibody and peroxidase-labelled streptavidin conjugated to HRP (DAKO LSAB ${ }^{2} 2$ System-HRP; Dako, Denmark). Color of sections was developed after incubation with DAB-chromogen solution (Dako, Denmark). The sections were then counterstained with Mayer's hematoxylin and mounted with an Entellan (Merck, USA). The slides were viewed with the microscope (Olympus BX41, Japan). The image capture was performed with Quick Photo Micro software, version 2.2 (Olympus, Japan). The density of activated caspase-3 immunoreactive cells (dark-brown cytoplasm; caspase 3 -IR) in the alveolar and bronchial epithelium was measured randomly from three sites within each section and was calculated as the total numbers of caspase 3-IR cells in the field.

\section{Lung edema formation (wet/dry weight ratio, WD ratio)}

Strips of the right lung were cut, weighed and dried at $60^{\circ} \mathrm{C}$ for $24 \mathrm{~h}$. Ratio between wet and dry weights of the lung tissue expressed the extent of fluid accumulation in the tissue.

\section{Data analysis}

Statistical analysis was performed using GraphPad Prism version 5.1 for Windows (GraphPad Software, USA). Statistical differences between the groups were determined by analysis of variance (ANOVA) with Bonferroni post-hoc test or with KruskalWallis test. Data are presented as means \pm SEM. Strength of association between respiratory parameters, biochemical and histopathological parameters and lung edema formation was evaluated by Pearson's correlations.
A value of $\mathrm{P}<0.05$ was considered significant.

\section{Results}

\section{Respiratory parameters and indexes}

Values of blood gases, respiratory parameters and indexes before and after induction of ALI were comparable between ALI and ALI+DEX group $(\mathrm{P}>0.05)$. Induction of ALI increased intrapulmonary shunting and worsened gas exchange. Treatment with dexamethasone tended to improve lung functions, however, the differences between ALI vs. ALI+DEX groups were not significant $(\mathrm{P}>0.05$; Table 1$)$.

\section{Cells in the BAL fluid}

In ALI group, higher number of cells in BAL was found compared to controls $(\mathrm{P}<0.01$, Fig. 1A). Dexamethasone decreased number of cells in BAL vs. ALI group ( $\mathrm{P}<0.05$, Fig. 1A).

Percentage of neutrophils increased in ALI group, but monocytes and macrophages decreased in ALI vs. Control groups (both $\mathrm{P}<0.001$, Fig. 1B). In ALI+DEX group, percentage of neutrophils decreased, and relative numbers of monocytes and macrophages elevated compared to ALI group (both $\mathrm{P}>0.001$, Fig. 1B).

\section{Markers of inflammation and lung injury}

Concentrations of pro-inflammatory cytokines (IL-1 $\beta$ and IL-8) in the lung of ALI animals increased vs. Control $(\mathrm{P}<0.05$ for IL-1 $\beta, \mathrm{P}<0.01$ for IL-8; Figs $2 \mathrm{~A}$ and 2B). Similarly, markers of epithelial injury (esRAGE) and endothelial injury (S1PR3) elevated in ALI animals vs. controls (both $\mathrm{P}<0.05$; Figs $2 \mathrm{C}$ and $2 \mathrm{D}$ ).

Dexamethasone decreased levels of IL-1 $\beta$ $(\mathrm{P}<0.05$; Fig. 2A) and esRAGE ( $<<0.05$; Fig. $2 \mathrm{C})$, but had no significant effect on IL-8 and S1PR3 (both $\mathrm{P}>0.05$ for; Figs 2B and 2D) vs. ALI group.
A

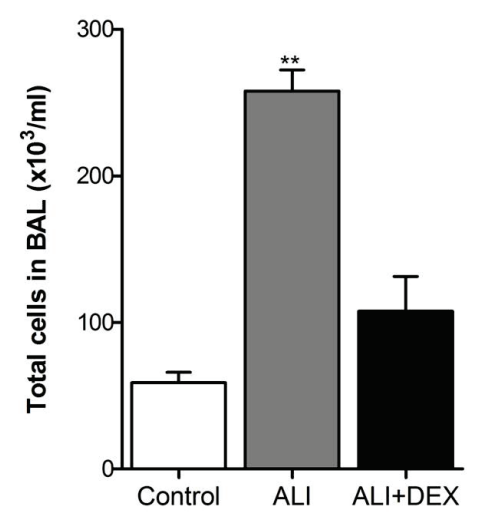

B

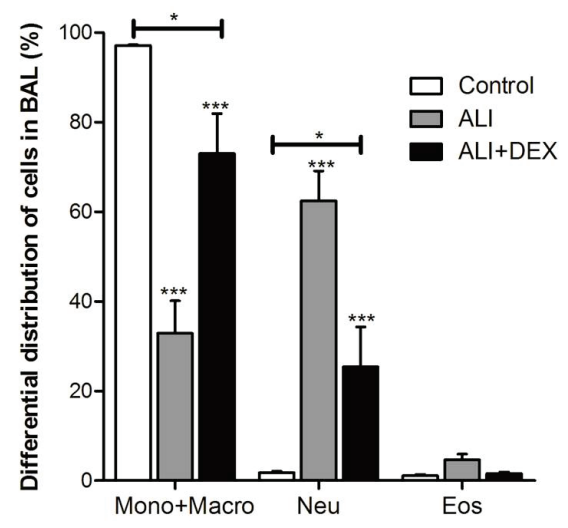

Fig. 1. Total and differential number of cells in BAL. (A) Total number of cells in the BAL fluid. (B) Differential count of cells in the BAL fluid. Mono-Macro - monocytesmacrophages, Neu - neutrophils, Eos eosinophils. Significant differences: $* \mathrm{P}<0.05$; ** $\mathrm{P}<0.01 ; * * * \mathrm{P}<0.001$, for ALI vs. Control, ALI+DEX vs. ALI, ALI+DEX vs. Control. 


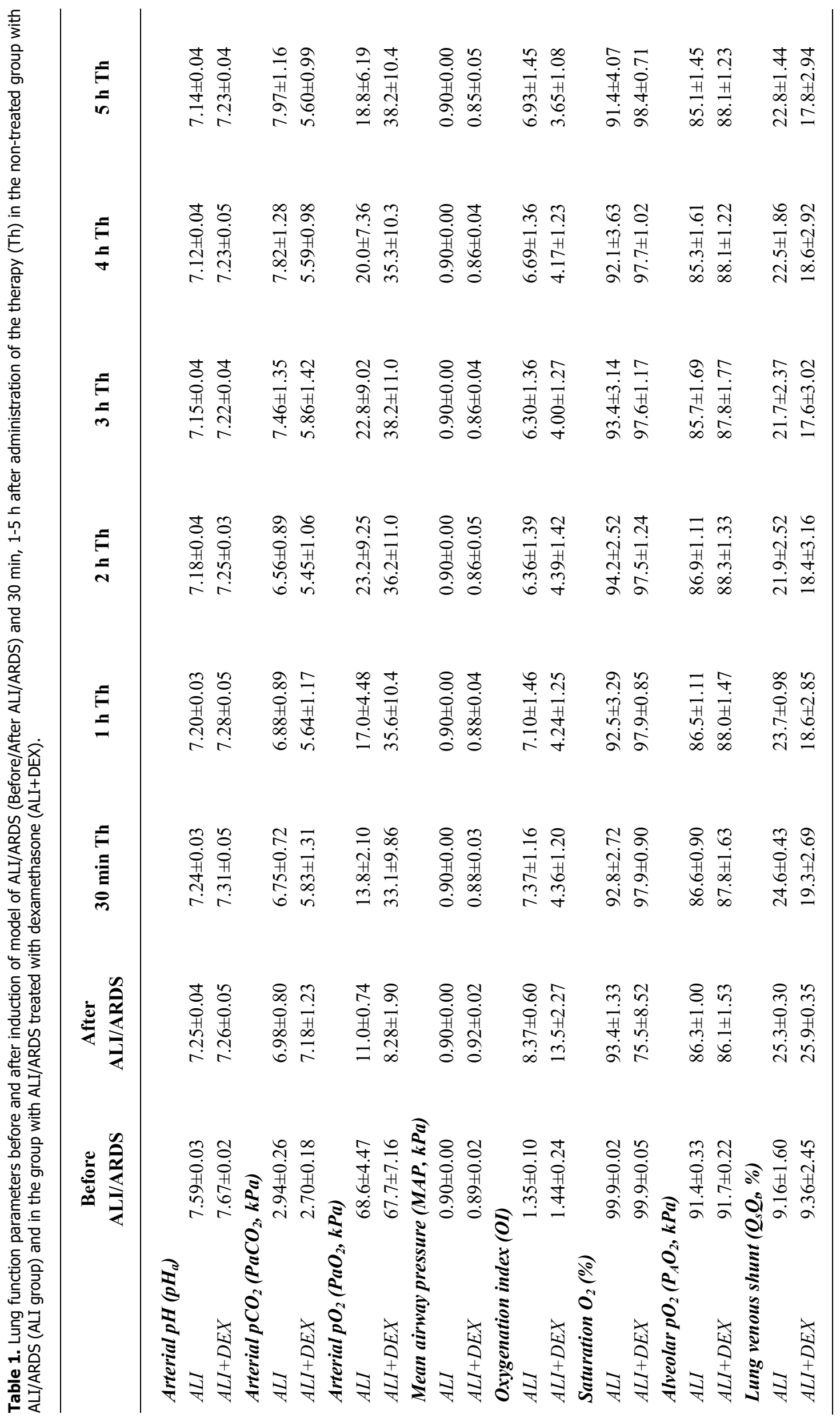


A

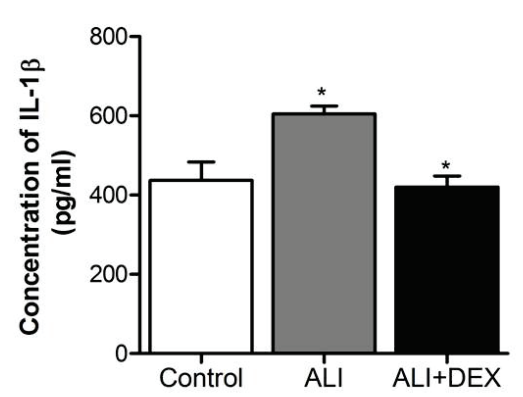

C

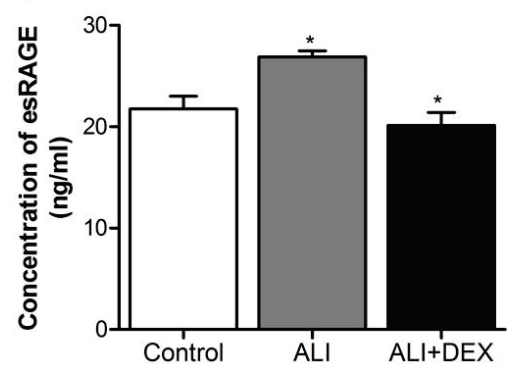

B

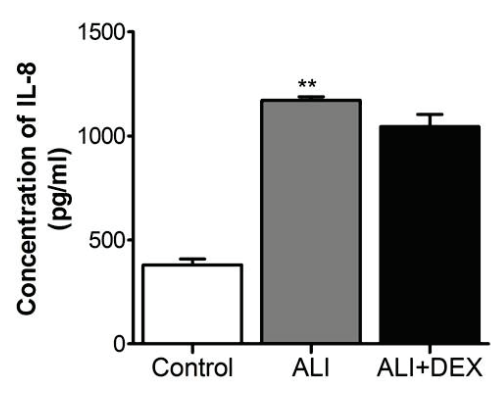

D

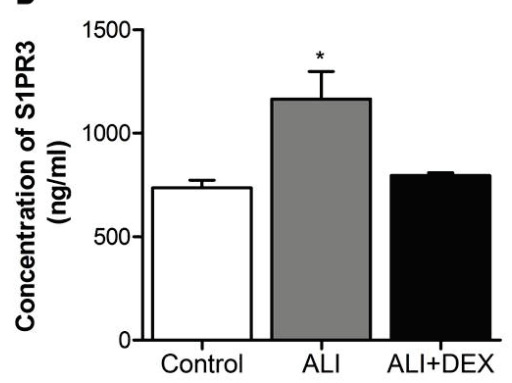

Fig. 2. Concentrations of markers of inflammation (IL-1 $\beta$, IL-8), epithelial (esRAGE) and endothelial (S1PR3) injury in the lung homogenates using an ELISA method, expressed in absolute values of concentration $(\mathrm{ng} / \mathrm{ml}, \mathrm{pg} / \mathrm{ml})$. IL interleukin, esRAGE - endogenous soluble receptor for advanced glycation endproducts, S1PR3 - sphingosine-1-phosphate receptor-3. Significant differences: * $\mathrm{P}<0.05$; $* * \mathrm{P}<0.01$; *** $\mathrm{P}<0.001$, for ALI vs. Control, ALI+DEX vs. ALI.
Histomorphological investigation of the lung

Induction of ALI increased occurance of atelectasis $(\mathrm{P}<0.01)$ and $\mathrm{PMN}$ infiltration $(\mathrm{P}<0.001)$ as well as total injury score $(\mathrm{P}<0.01)$ compared to controls, whereas increase in occurance of emphysema and hemorrhagia was not significant. Dexamethasone reduced PMN infiltration $(\mathrm{P}<0.05)$ and showed a tendency to improve the other markers of injury, as well (Table 2).

\section{Apoptosis in the lung tissue}

Number of caspase-3 immunoreactive cells in the lung increased in ALI animals vs. controls $(\mathrm{P}<0.05$; Fig. 3A). In dexamethasone-treated animals, number of caspase-3 IR cells even increased compared to untreated ALI animals ( $\mathrm{P}<0.001$; Fig. 3A).

Apoptotic index (number of TUNEL-positive cells/number of DAPI-stained cells) significantly elevated in animals with ALI compared to controls $(\mathrm{P}<0.001)$ and decreased in DEX-treated animals $(\mathrm{P}<0.01$; Fig. $3 \mathrm{~B})$.

\section{Lung edema formation}

Repetitive saline lung lavage caused fluid accumulation in the tissue in ALI group compared with Control $(\mathrm{P}<0.01)$. Dexamethasone reduced edema formation compared to non-treated ALI animals $(\mathrm{P}<0.05)$ (Table 2). Pearson's correlations showed strong positive correlation of WD ratio with above mentioned histopathological signs, with numbers of cells and neutrophils in the BAL fluid, IL-1 $\beta$, and with oxygenation index and venous shunts (data not shown).

\section{Discussion}

The acute phase of ALI/ARDS in humans is characterized by neutrophil-mediated inflammation, injury and apoptosis of lung cells, and edema formation. In our study, repetitive lung lavage in rabbits induced migration of neutrophils into the alveolar space, increased production of pro-inflammatory cytokines and markers of epithelial and endothelial injury, and triggered apoptosis of epithelial cells. Intravenous dexamethasone mitigated lung inflammation, injury, and edema formation, modulated apoptotic changes, and tended to improve gas exchange in rabbits with ALI.

Considering the changes mentioned in ALI/ARDS, GCs may be of benefit as they suppress inflammation, promote alveolar fluid clearance, stimulate surfactant production, and reduce neutrophil recruitment (Coutinho and Chapman 2011). Positive effects of GCs have been previously shown in other models of ALI (Wang et al. 2005, Mokra et al. 2007, Mikolka et al. 2013). In this study, percentage of neutrophils in the BAL fluid increased within $5 \mathrm{~h}$ after induction of ALI, as dysfunction of the alveolar-capillary barrier enhanced transmigration of leukocytes into the lung. Activated cells generated pro-inflammatory cytokines (e.g. IL-1 $\beta$ and IL-8), as we could detect their higher concentrations in the lung tissue at the end of experiment. IL- $1 \beta$ and IL- 8 serve as sensitive biomarkers of ALI/ARDS also in patients where their increased concentrations often correlate with increased mortality (Bhargava and Wendt 
2012). Treatment with dexamethasone in our study decreased IL-1 $\beta$ and tended to decrease IL- 8 in the lung tissue. Reduced expression of pro-inflammatory substances including cytokines after GCs was previously published also by others (Kovalovsky et al. 2000).

Table 2. Wet-dry (WD) lung weight ratio and histological examination of the lung tissue in the healthy controls (Control group), in the non-treated group with ALI/ARDS (ALI group), and in the group with ALI/ARDS treated with dexamethasone (ALI+DEX).

\begin{tabular}{lcccccc}
\hline & WD ratio & Atelectasis & Emphysema & Hemorrhagia & $\begin{array}{c}\text { PMN } \\
\text { infiltration }\end{array}$ & TIS \\
\hline Control & $4.4 \pm 0.1$ & $0.4 \pm 0.2$ & $0.4 \pm 0.2$ & $0.4 \pm 0.2$ & $0.6 \pm 0.2$ & $1.8 \pm 0.9$ \\
$A L I$ & $6.0 \pm 0.2^{*}$ & $2.1 \pm 0.3^{*}$ & $1.4 \pm 0.5$ & $1.3 \pm 0.5$ & $2.4 \pm 0.2^{\$}$ & $7.4 \pm 0.9^{*}$ \\
$A L I+D E X$ & $4.9 \pm 0.2^{\#}$ & $1.4 \pm 0.5$ & $1.0 \pm 0.4$ & $0.8 \pm 0.6$ & $1.6 \pm 0.2^{\#}$ & $4.8 \pm 1.5$ \\
\hline
\end{tabular}

PMN - polymorphonuclears, TIS - total lung injury score. Significant differences between ALI vs. Control groups: ${ }^{*} \mathrm{P}<0.01 ;{ }^{\$} \mathrm{P}<0.001$; between ALI+DEX vs. ALI groups: ${ }^{\#} \mathrm{P}<0.05$.

B

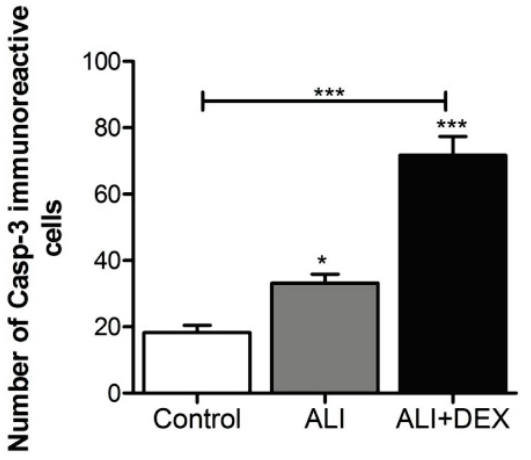

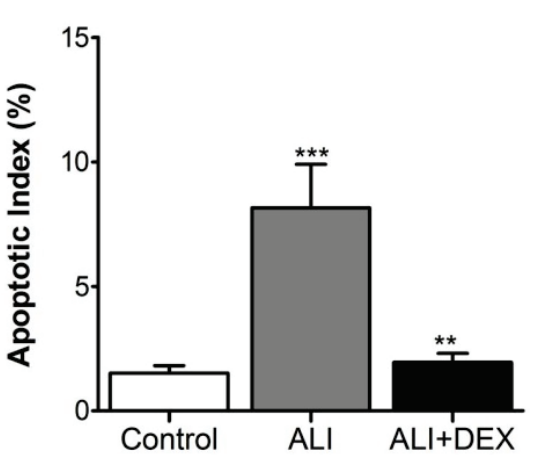

Fig. 3. Apoptosis in the lung tissue. (A) Number of caspase-3 immunoreactive cells in the lung tissue. (B) Apoptotic index of cells in the lung expressed as a ratio between a number of TUNEL-positive cells and number of DAPI-stained cells. Significant differences: * $\mathrm{P}<0.05 ; * * \mathrm{P}<0.01$; $* * * P<0.001$, for ALI vs. Control, ALI+DEX vs. ALI, ALI+DEX vs. Control.
The early phase of ALI is also associated with injury to epithelial and endothelial lung cells. Histological investigation showed significantly increased atelectasis, PMN infiltration and worsened total lung injury score, whereas occurance of emphysema and hemorrhagia was less obvious. Injury to type I alveolar cells was additionally verified by increased concentration of endogenous soluble receptor for advanced glycation end products (esRAGE) which is responsible for propagation of inflammatory response via nuclear factorkappa B (NF- $\mathrm{B})$, thus increasing production of proinflammatory cytokines, ROS, and proteases, as well (Uchida et al. 2006). Injury to endothelial cells was expressed by increased concentration of sphingosine-1phosphate receptor-3 (S1PR3) which directly participates in the regulation of vascular permeability (Singleton et al. 2006) and promotes recruitment of inflammatory cells, such as monocytes/macrophages (Keul et al. 2011). Expression of S1PR3 is critical for disruption of endothelial cell barriers in vivo and in vitro (Singleton et al. 2006). In this study, histomorphological signs and biochemical markers of lung cell injury have confirmed serious injury of the lung tissue already within $5 \mathrm{~h}$ after induction of ALI. Dexamethasone decreased PMN infiltration and level of esRAGE, and tended to decrease S1PR3 and histological signs of lung injury.

Lung injury can be further aggravated by increased apoptosis of epithelial cells. On the other hand, apoptosis of neutrophils is delayed, thus they can persist longer at a site of injury and deteriorate the tissue by their products. Programmed cell death (apoptosis) is induced through two pathways. The intrinsic pathway is mitochondria-dependent and is activated by ROS or cytokines. The extrinsic pathway is dependent on inflammatory molecules, such as TNF- $\alpha$ or Fas-ligand. Activating production of ROS via NADPH oxidase, TNF- $\alpha$ contributes to the intrinsic pathway, as well. Both pathways lead to activation of initiator caspases- 8 or -9 and finally to activation of effector caspase-3, which is responsible for execution of cell death (Galani et al. 2010). In our study, number of caspase-3 immunoreactive cells and apoptotic index in the lung sections significantly 
increased in ALI animals compared to controls, indicating activation of pro-apoptotic processes early after the lavage-induced ALI.

GCs can modulate apoptosis by several mechanisms, whereas the pro- or anti-apoptotic effects of dexamethasone are cell type-dependent. For instance, dexamethasone induces apoptosis in $\mathrm{T}$ and B-lymphocytes, monocytes, eosinophils and both activated and non-activated peripheral blood mononuclear cells (Amsterdam et al. 2002, McColl et al. 2007). Dexamethasone generally protects from apoptosis the non-immune cells including lung epithelial cells and thereby protects them from ongoing inflammatory damage (Amsterdam et al. 2002). Pro-apoptotic action of dexamethasone include direct activation of pro-apoptotic members of Bcl-2 family such as Bcl-2, Bad, and Bcl-XL (Nagata et al. 1997), suppression of cell survival factors such as AP-1 (Angel and Karin 1991) or interaction of GR with pro-apoptotic death-associated protein DAP3 (Hulkko et al. 2000). Indirect suppression of antiapoptotic cytokines by GCs may cause apoptosis in various cell types. Dexamethasone can induce apoptosis via altered signaling of the key inflammatory transcription factor NF- $\mathrm{BB}$ (Karin and Lin 2002). In this study, number of caspase- 3 immunoreactive cells elevated after dexamethasone, but in the same tissue the apoptotic index decreased. Complex action of GCs on both pro- and anti-apoptotic processes in different types of cells present in the lung could be responsible for this discrepancy. Moreover, activation of caspase-3 and detection of TUNEL-labeled DNA strand breaks as a final product of apoptosis could represent two processes in different time relations. In lung epithelial cell cultures, dexamethasone inhibited caspase-3 activation and expression of the Fas ligand (Wen et al. 1997, Beck et al. 2009). In other study, dexamethasone treatment in rats with pulmonary arterial hypertension increased caspase-3 expression and DNA fragmentation in pulmonary artery smooth muscle cells (Price et al. 2015).

The complex influence of damage to alveolarcapillary lining cells and increased recruitment of inflammatory cells into the alveolar space leads to edema formation. Pulmonary edema is associated with both local and systemic inflammation (Goodman et al. 2003). In addition, hypoxia-induced pulmonary vasoconstriction elevates capillary hydrostatic filtration pressure and permeability (Murray 2011). In this study, lung edema formation expressed as lung wet/dry ratio increased in untreated ALI animals vs. controls and correlated both with histomorphological changes in the tissue, numbers of cells and neutrophils in the BAL fluid, IL-1 $\beta$, and with oxygenation index and venous shunts. Dexamethasone therapy decreased fluid accumulation in the lung probably due to stabilization of membranes and reduced microvascular permeability, as well as reduced local inflammation. This finding is in agreement with other authors (Lefort et al. 2001).

The above mentioned changes in the lung tissue seriously worsened the respiratory parameters after induction of ALI compared to initial values. Administration of dexamethasone slightly enhanced gas exchange and reduced right-to-left shunting compared to non-treated animals. Whereas this effect could be observed within the first hour after treatment delivery, we can presume participation of non-genomic mechanisms of GCs (Coutinho and Chapman 2011).

In conclusion, intravenous dexamethasone decreased a leak and activation of neutrophils in the lung, mitigated inflammation, cell injury and lung edema formation, modulated lung cell apoptosis, and slightly enhanced the respiratory parameters in animals with saline lavage-induced model of ALI.

\section{Conflict of Interest}

There is no conflict of interest.

\section{Acknowledgements}

The study was supported by projects APVV-0435-11, APVV-15-0075, VEGA 1/0305/14, and Grant UK/28/2015. This work was supported also by the project „Biomedical Center Martin“ ITMS code: 26220220187 , co-financed from EU sources.

\section{References}

AMSTERDAM A, TAJIMA K, SASSON R: Cell-specific regulation of apoptosis by glucocorticoids: implication to their anti-inflammatory action. Biochem Pharmacol 64: 843-850, 2002.

ANGEL P, KARIN M: The role of Jun, Fos and the AP-1 complex in cell-proliferation and transformation. Biochim Biophys Acta 1072: 129-157, 1991. 
BECK JM, PRESTON AM, WILCOXEN SE, MORRIS SB, STURROCK A, PAINE R 3RD: Critical roles of inflammation and apoptosis in improved survival in a model of hyperoxia-induced acute lung injury in Pneumocystis murina-infected mice. Infect Immun 77: 1053-1060, 2009.

BHARGAVA M, WENDT CH: Biomarkers in acute lung injury. Transl Res 159: 205-217, 2012.

CHIANG ST: A nomogram for venous shunt (Qs-Qt) calculation. Thorax 23: 563-565, 1968.

COUTINHO AE, CHAPMAN KE: The anti-inflammatory and immunosuppressive effects of glucocorticoids, recent developments and mechanistic insights. Mol Cell Endocrinol 335: 2-13, 2011.

GALANI V, TATSAKI E, BAI M, KITSOULIS P, LEKKA M, NAKOS G, KANAVAROS P: The role of apoptosis in the pathophysiology of Acute Respiratory Distress Syndrome (ARDS): an up-to-date cell-specific review. Pathol Res Pract 206: 145-150, 2010.

GOODMAN RB, PUGIN J, LEE JS, MATTHAY MA: Cytokine-mediated inflammation in acute lung injury. Cytokine Growth Factor Rev 14: 523-535, 2003.

GROMMES J, SOEHNLEIN O: Contribution of neutrophils to acute lung injury. Mol Med 17: 293-307, 2011.

HOUGH CL: Steroids for acute respiratory distress syndrome? Clin Chest Med 35: 781-795, 2014.

HULKKO SM, WAKUI H, ZILLIACUS J: The pro-apoptotic protein death-associated protein 3 (DAP3) interacts with the glucocorticoid receptor and affects the receptor function. Biochem J 349: 885-893, 2000.

KARIN M, LIN A: NF-kappaB at the crossroads of life and death. Nat Immunol 3: 221-227, 2002.

KEUL P, LUCKE S, VON WNUCK LIPINSKI K, BODE C, GRÄLER M, HEUSCH G, LEVKAU B: Sphingosine-1phosphate receptor 3 promotes recruitment of monocyte/macrophagesin inflammation and atherosclerosis. Circ Res 108: 314-323, 2011.

KOVALOVSKY D, REFOJO D, HOLSBOER F, ARZT E: Molecular mechanisms and Th1/Th2 pathways in corticosteroid regulation of cytokine production. J Neuroimmunol 109: 23-29, 2000.

LEFORT J, MOTREFF L, VARGAFTIG BB: Airway administration of Escherichia coli endotoxin to mice induces glucocorticosteroid-resistant bronchoconstriction and vasopermeation. Am J Respir Cell Mol Biol 24: 345-351, 2001.

LOWRY OH, ROSEBROUGH NJ, FARR AL, RANDALL RJ: Protein measurement with the Folin phenol reagent. J Biol Chem 193: 265-275, 1951.

MATTHAY MA, ZEMANS RL: The acute respiratory distress syndrome: pathogenesis and treatment. Annu Rev Pathol 6: 147-163, 2011.

MCCOLL A, MICHLEWSKA S, DRANSFIELD I, ROSSI AG: Effects of glucocorticoids on apoptosis and clearance of apoptotic cells. Scientific WorldJournal 7: 1165-1181, 2007.

MEDURI GU, MARIK PE, ANNANE D: Prolonged glucocorticoid treatment in acute respiratory distress syndrome: Evidence supporting effectiveness and safety. Crit Care Med 37: 1800-1803, 2009.

MIKOLKA P, MOKRA D, KOPINCOVA J, TOMCIKOVA-MIKUSIAKOVA L, CALKOVSKA A: Budesonide added to modified porcine surfactant Curosurf may additionally improve the lung functions in meconium aspiration syndrome. Physiol Res 62 (Suppl 1): S191-S200, 2013.

MOKRA D, MOKRY J, DRGOVA A, BULIKOVA J, PETRASKOVA M, CALKOVSKA A: Single-dose versus twodose dexamethasone effects on lung inflammation and airway reactivity in meconium-instilled rabbits. J Physiol Pharmacol 58 (Suppl 5): 379-387, 2007.

MURRAY JF: Pulmonary edema: pathophysiology and diagnosis. Int J Tuberc Lung Dis 15: 155-160, 2011.

NAGATA S: Apoptosis by death factor. Cell 88: 355-365, 1997.

PRICE LC, SHAO D, MENG C, PERROS F, GARFIELD BE, ZHU J, MONTANI D, DORFMULLER P, HUMBERT M, ADCOCK IM, WORT SJ: Dexamethasone induces apoptosis in pulmonary arterial smooth muscle cells. Respir Res 16: 114, 2015.

SINGLETON PA, DUDEK SM, MA SF, GARCIA JG: Transactivation of sphingosine 1-phosphate receptors is essential for vascular barrier regulation. Novel role for hyaluronan and CD44 receptor family. J Biol Chem 281: 34381-34393, 2006.

TANG BM, CRAIG JC, ESLICK GD, SEPPELT I, MCLEAN AS: Use of corticosteroids in acute lung injury and acute respiratory distress syndrome: a systematic review and meta-analysis. Crit Care Med 37: 1594-1603, 2009. 
UCHIDA T, SHIRASAWA M, WARE LB, KOJIMA K, HATA Y, MAKITA K, MEDNICK G, MATTHAY ZA, MATTHAY MA: Receptor for advanced glycation end-products is a marker of type I cell injury in acute lung injury. Am J Respir Crit Care Med 173: 1008-1015, 2006.

WANG HM, BODENSTEIN M, MARKSTALLER K: Overview of the pathology of three widely used animal models of acute lung injury. Eur Surg Res 40: 305-316, 2008.

WANG J, WINSKOG C, EDSTON E, WALTHER SM: Inhaled and intravenous corticosteroids both attenuate chlorine gas-induced lung injury in pigs. Acta Anaesthesiol Scand 49: 183-190, 2005.

WEN LP, MADANI K, FAHRNI JA, DUNCAN SR, ROSEN GD: Dexamethasone inhibits lung epithelial cell apoptosis induced by IFN-gamma and Fas. Am J Physiol 273: L921-L929, 1997. 